\title{
Effects of cinchonine, a Cinchona bark alkaloid, on spontaneous and induced rat ileum contractions
}

\author{
Rankovic $\mathrm{G}^{1}$, Stankovic $\mathrm{V}^{1}$, Zivkovic $\mathrm{M}^{1}$, Rankovic $\mathrm{B}^{2}$, Laketic $\mathrm{D}^{1}$, Potic $\mathrm{M}^{3}$, \\ Saranovic $\mathrm{M}^{1}$, Nedin Rankovic $\mathrm{G}^{3}$
}

University of Priština, Kosovska Mitrovica, Serbia. goran.rankovic@pr.ac.rs

\begin{abstract}
AIM: Quinine, a frequently used anti-malaria alkaloid isolated from the Cinchona bark, possesses numerous toxic properties, the majority of which arrive from a dysfunction of the gastrointestinal tract. Similarly, cinchonine, another alkaloid from the Cinchona bark, displays a great potential for treating malaria (especially the resistant forms). METHODS: In this work, we aimed to evaluate the effects of cinchonine on spontaneous and induced Wistar rat ileum contractions in order to uncover potential side effects that might arise after its application.

RESULTS: Cinchonine produced a concentration-dependent spasmolytic activity, which was found to be reversible (i.e. disappeared after tissue wash-up), with an $\mathrm{IC}_{50}$ value of $273 \mu \mathrm{M}$. Furthermore, the mechanism of action of cinchonine at $\mathrm{IC}_{50}$ elucidated through experiments with acetylcholine and $\mathrm{Ca}^{2+}$-induced ileum contractions. The applied $\mathrm{IC}_{50}$ concentration of cinchonine statistically significantly prevented the occurrence of contractions after the application of specific agonist. The obtained results are in a range with the effects seen with standard receptor antagonists, i.e. atropine and verapamil.

CONCLUSIONS: The obtained results showed that cinchonine inhibited both types of induced contractions, suggesting a $\mathrm{Ca}^{2+}$-channels mediated modus operandi (Fig. 4, Ref. 19). Text in PDF www.elis.sk.

KEY WORDS: cinchonine, Cinchona bark, ileum, spasmolytic, calcium channels.
\end{abstract}

\section{Introduction}

Cinchonine (Cin) (Fig. 1) is an alkaloid isolated from the bark of trees belonging to Cinchona and Ramijia (Rubiaceae) genera. Cinchona bark was found at the beginning of the twentieth century to possess significant antimalarial properties, however, the crude extract of this bark failed to be commercialized due to significant variations in its composition. Apart from Cin, Cinchona bark extract contains three other alkaloids, quinine, quinidine, and cinchonidine, and it is suggested that a synergistic action of several alkaloids is the main reason for the extract's activity (1). The commercial combination containing quinine, quinidine, and Cin seems to be a promising agent acting against quinine-resistant Plasmodium falciparum (2). It is considered that Cin is the second most important alkaloid from this tree bark after quinine. Cinchonine found its application as an antimalarial drug as well (3), but most frequently it is applied for the treatment of gastrointestinal tract-born infections such as schistosomiasis, amebiasis, dysentery, etc. (4). The possible application of Cin for the treatment of

${ }^{1}$ University of Priština, Kosovska Mitrovica, Serbia, ${ }^{2}$ University of Ljubljana, Ljubljana, Slovenia, and ${ }^{3}$ Faculty of Medicine, University of Niš, Niš, Serbia

Address for correspondence: G. Rankovic, University of Priština, Filipa Visnjica nn, 38220 Kosovska Mitrovica, Serbia.

Phone:+38128422340, Fax: +38128422320<smiles>C=C[C@H]1CN2CC[C@H]1C[C@H]2[C@H](O)c1ccnc2ccccc12</smiles>

Fig. 1. Chemical structure of cinchonine (Cin).

malaria lies in its lower toxicity compared to that of quinine and a higher potency toward the parasite relative to other quininerelated compounds (5).

Besides the mentioned properties of Cin, the recent studies showed that this alkaloid could act as a potential anti-obesity drug. In mice fed with a high-fat diet, the application of Cin led to a significant amelioration in their serum lipid profile (triglyceride, cholesterol, HDL and LDL levels) and glucose level changes caused by this type of diet (6). Also, Cin was found to suppress TLR2- and TLR4-mediated inflammatory response in adipose tissue of animals with early symptoms of the metabolic syndrome and associated disorders (6). The antiaggregatory activity of Cinusing on human platelets was shown to involve an inhibition of $\mathrm{Ca}^{2+}$ ions influx and protein kinase $\mathrm{C}$ pathway (7). 
Antimalarial drugs, both old and new generation ones, are known to cause numerous side effects that could affect almost every organ system (8). Although quinine is of natural origin, its application is far from being safe. It exerts most pronouncedly toxic effects on the cardiovascular system, as it also passes into the brain tissue it causes vertigo, tinnitus, headache, depression of respiration, convulsions and even coma (8). Besides the cardiovascular and central nervous system (CNS) related symptoms, quinine can cause so-called cinchonism. This represents a combination of symptoms that include CNS function alteration and gastrointestinal disturbances $(8,9)$. In many cases, a mild nausea can be the only symptom occurring in these patients, however, it can cause a profuse vomiting, abdominal pain, and diarrhoea. These disturbances in the gastrointestinal system are believed to be the consequence of direct irritant properties of quinine (9).

In this light, we aimed to evaluate whether cinchonine (Cin), which could be considered a suitable substitute for quinine in malaria therapy, affects a spontaneous motility of a gastrointestinal segment (ileum) isolated from rats. Also, the effects of Cin on acetylcholine (Ach)- and $\mathrm{Ca}^{2+}$-induced contractions of rat ileum were studied in order to possibly uncover the underlying mechanism of the action of Cin.

\section{Materials and methods}

\section{Drugs and chemicals}

All chemicals used in this study were of analytical grade and were obtained from either Sigma Aldrich (USA) or Roth (Germany). Cinchonine ( $\geq 98.0 \%$ purity) was also purchased from Sigma Aldrich, and a stock solution of $25 \mathrm{mg} / \mathrm{ml}$ was prepared on daily basis. Atropine, as atropine sulfate, was obtained from Sopharma AD (Sofia, Bulgaria) in a form of injection solution at a concentration of $1 \mathrm{mg} / \mathrm{ml}$. Verapamil, as verapamil hydrochloride, was purchased from Alkaloid (Skopje, Northern Macedonia) in a form of injection solution at a concentration of $2.5 \mathrm{mg} / \mathrm{ml}$. Tyrode's solution was prepared fresh, just before the experiment and consisted of $150 \mathrm{mM} \mathrm{NaCl}, 2.7 \mathrm{mM} \mathrm{KCl}, 2 \mathrm{mM} \mathrm{MgCl}_{2}, 1.8$ $\mathrm{mM} \mathrm{CaCl}_{2}, 0.4 \mathrm{mM} \mathrm{NaH}_{2} \mathrm{PO}_{4}, 12 \mathrm{mM} \mathrm{NaHCO}_{3}$, and $5.5 \mathrm{mM}$ of glucose. In the case when calcium-free Tyrode's solution was used, $\mathrm{CaCl}_{2}$ was substituted with $\mathrm{KCl}$.

\section{Animals and housing}

Three-month-old male Wistar rats (250-300 g) were obtained from the animal facilities of the Faculty of Medicine, University of Niš, Serbia. The animals were housed under standard husbandry conditions, which included an ambient temperature $20-22{ }^{\circ} \mathrm{C}$ and a 12/12 h light/dark cycle, with free access to food and water. All experiments were done in accordance with the Council of Europe Directive of $22^{\text {nd }}$ September 2010 (Directive 2010/63/EU) and were pre-approved by the Animal Ethics Committee of the Faculty of Medicine, University of Niš.

\section{Ileum-tissue isolation and sample mounting}

After scarification, the animal abdominal cavity was opened, the ileocecal transition was found and $1 \mathrm{~cm}$ from the flexure of the intestine was cut and the segment of the ileum was dissected. The dissected segment was placed in a petri dish filled with Tyrode's solution where it was cleaned from the surrounding mesenteries and any luminal content was washed. From each animal, four segments, $2 \mathrm{~cm}$ in length, were used per experiment, all experiments were repeated twice. Tissue segments were placed in a bath filled with Tyrode's solution and were constantly aerated with a mixture of $5 \% \mathrm{CO}_{2}$ and $95 \%$ of $\mathrm{O}_{2}$, and heated at $37{ }^{\circ} \mathrm{C}$. One end of the ileum was anchored to the bottom of the tissue bath, while the other was connected by the means of a cotton thread to a transducer (TSZ-04-E, Experimetria Ltd, Budapest, Hungary). Before the experiment was commenced, the mounted ileum segments were left to adapt to the conditions for $45 \mathrm{~min}$ and the solution was changed every $15 \mathrm{~min}$.

\section{Effect of Cin on ileum spontaneous contractions (spontaneous peristaltic)}

After the adaptation period, ileum tissue was exposed to an increasing concentration of Cin ranging from 1 to $500 \mu \mathrm{M}$. After each concentration, Tyrode's solution was removed and the bath was filled with a fresh amount, after which the tissue was left to return to its basal tone. The change in the contraction force under the influence of different Cin concentrations was calculated as a change in the area under the curve compared to the baseline value. Values obtained from the change in ileum contraction force under the impact of Cin were used to construct a curve, from where an $\mathrm{IC}_{50}$ value was calculated. The obtained $\mathrm{IC}_{50}$ value was further used in experiments designated to determine the possible underlying mechanism of action of Cin.

\section{Effect of Cin on acetylcholine-induced contractions}

In order to corroborate the potential involvement of Ach receptors in the spasmolytic activity of Cin, we used acetylcholine as the Ach-receptor agonist. Rising concentrations of acetylcholine $(0.1-10 \mu \mathrm{M})$ were added to the bath with an ileum preparation and the changes in the contractions were recorded for $60 \mathrm{~s}$ after the exposure to Ach. When the dose-response curves were constructed, the tissue was incubated with $\mathrm{IC}_{50}$ of Cin for $3 \mathrm{~min}$, followed by the exposure to a single dose of Ach. Atropine (140 $\mathrm{nM}$ ), a nonselective muscarinic receptor antagonist, was used as a positive control and was added in the same manner as Cin. After each exposure to Ach, during $60 \mathrm{~s}$, the tissue was washed and the bath was filled with a fresh amount of Tyrode's solution.

\section{Effect of Cin on $\mathrm{Ca}^{2+}$-induced contractions}

The involvement of $\mathrm{Cin}$ on $\mathrm{Ca}^{2+}$-induced contractions was investigated using the ileum tissue that was exposed to a calciumfree Tyrode's solution for 30 minutes before the experiments were commenced. As in the case of Ach-induced contraction, the ileum preparation was exposed to increasing concentrations $\left(10^{-7}-3 \times 10^{-4}\right.$

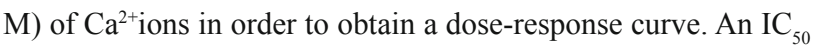
dose of Cin was added to the bath 3 min prior to a single concentration of $\mathrm{Ca}^{2+}$ solution. Verapamil $(1 \mu \mathrm{M})$, a voltage depended $\mathrm{Ca}^{2+}$-channel blocker, was used as a positive control in this set of experiments and was added to a bath in the same manner as Cin. 


\section{$576-580$}

After each exposure to a specific solution of $\mathrm{Ca}^{2+}$, during $60 \mathrm{~s}$, the tissue was washed and the bath was filled with a fresh amount of calcium-free Tyrode's solution.

\section{Data analysis and comparison}

Contraction patterns, recorded during each set of experiments, were analysed using the SPEL Advanced ISOSYS Data Acquisition System (Experimetria Ltd). The measurement was performed after setting a baseline value for each segment of ileum, where the initial measurement was obtained from an unexposed ileum tissue. An increase in ileum tissue contraction under the influence of Ach or $\mathrm{Ca}^{2+}$, with or without other substances, was calculated as a change in the area under the curve and the data were expressed as $\%$ of maximal contraction. Also, the period required for Achinduced contraction to reach its maximal amplitude (PMA) was calculated from the time of Ach administration, with or without other substances, to the maximal amplitude (10). The results are presented as the mean values \pm standard deviations (SD) and mutually compared using either Student's t-test or One-Way ANOVA, followed by and Tukey's post-hoc test (GraphPad Prism, ver. 5.03; San Diego, CA). Probability values were taken to be statistically significant if $\mathrm{p}$ was less or equal to 0.05 .

\section{Results and discussion}

Increasing concentrations of Cin were found to reduce the intensity of spontaneous rat ileum contractions (Fig. 2). A significant decrease in contraction intensity was observed after the application of Cin at concentrations $\geq 10 \mu \mathrm{M}$ (Fig. 2). This type of contraction decrease under the influence of Cin was found to be dose dependent $(\mathrm{p}>0.05)$. As mentioned in the materials and methods section, after constructing the dose-response curve, $\mathrm{IC}_{50}$ value was calculated, and the obtained value was found to be 273 $\mu \mathrm{M}$. Similarly, however, in 100 times lower concentrations, quinine produced a contraction-dependent relaxation of the isolated rat ileum tissue, which was attributed to a clear fall in intracellu- lar free $\mathrm{Ca}^{2+}$ concentration (11). Since the efflux of $\mathrm{Ca}^{2+}$ ions and its release from the intracellular compartment has been proven to be crucial for the excitation-contraction coupling mechanism (11), we could speculate that $\mathrm{Cin}$ also probably affects $\mathrm{Ca}^{2+}$ ion concentrations. The mechanism of action of renown naturally occurring antispasmodic agents, such as papaverine, also include the modulation of $\mathrm{Ca}^{2+}$ concentration through the change in cyclic AMP activity (12). The connection between the cAMP and $\mathrm{Ca}^{2+}$ is well studied mechanism for adrenergic receptor agonists, which are known to cause a smooth muscle relaxation through an increase in cAMP activity (13). Although the involvement of cAMP is found to be the link between the contraction and relaxation, the involvement of this enzyme was ruled out from the spasmolytic mechanism of action of quinine (14). Thus, due to the structure similarities between quinine and Cin, we would not expect of Cin to act on cAMP either.

The application of increasing concentrations of Ach (0.1-10 $\mu \mathrm{M})$ caused an increase in ileum smooth muscle contractions, which was abolished by the application of $\mathrm{Cin}$ at its $\mathrm{IC}_{50}$ concentration (Fig. 3A). The displacement of the constructed contraction intensity curve was towards the right and in a non-parallel manner compared to the control Ach-constructed curve (Fig. 3A). Previous studies conducted using quinine and its synthetic analogue, mefloquine, showed a similar pattern of activity towards Ach-induced guinea pig ileum contractions (15). However, the effective concentrations of those two alkaloids applied prior to Ach were around 3 to 10 times lower than the one applied in our study.

The application of Ach in a concentration as low as $10^{-6} \mathrm{M}$ caused tonic contraction (Fig. 3A), and the period, in which the contractions reached maximal amplitude, was around 8 seconds (Fig 3B). The incubation of ileum tissue with Cin at its $\mathrm{IC}_{50}$ concentration prior to the addition of Ach had no significant effect on the period required for Ach-induced contraction to reach its maximal amplitude (PMA), although PMA was slightly prolonged (Fig. 3B). A nonselective muscarinic receptor antagonist, atropine (140 $\mathrm{nM}$ ), reduced PMA that follows Ach administration (Fig. 3B). The

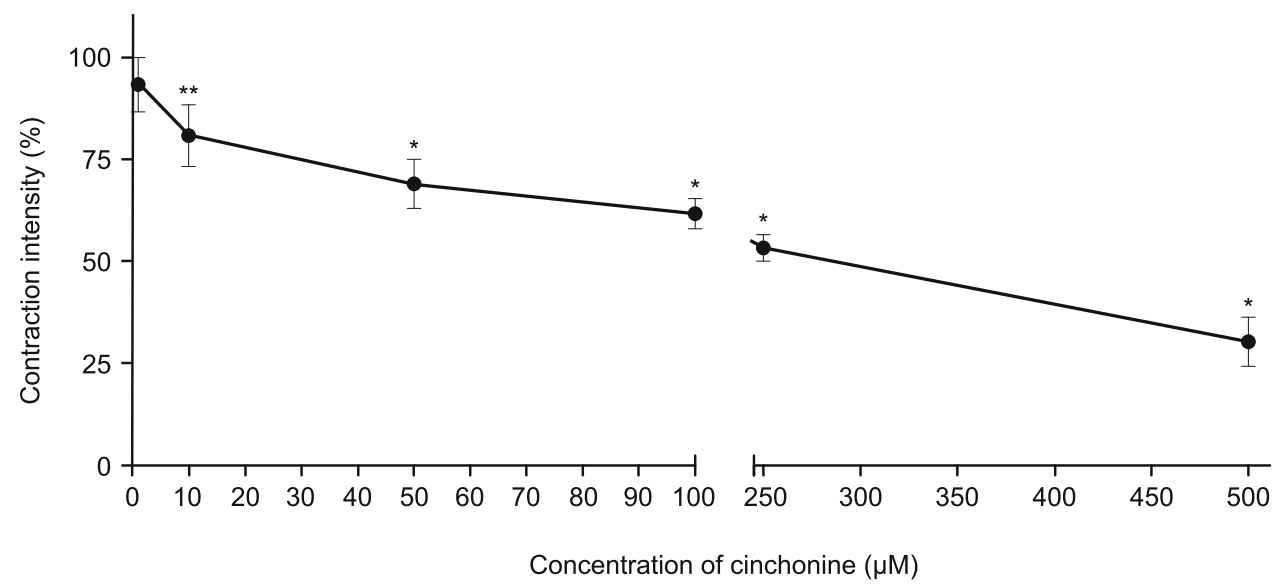

Fig. 2. Effect of Cin on rat ileum contractile response. Data are presented as the mean $\pm \mathrm{SD}(\mathrm{n}=\mathbf{8}) ; * \mathbf{p}<0.001$ and ** $\mathbf{p}<0.01$ vs. control (untreated tissue segment contractions). 
(A)

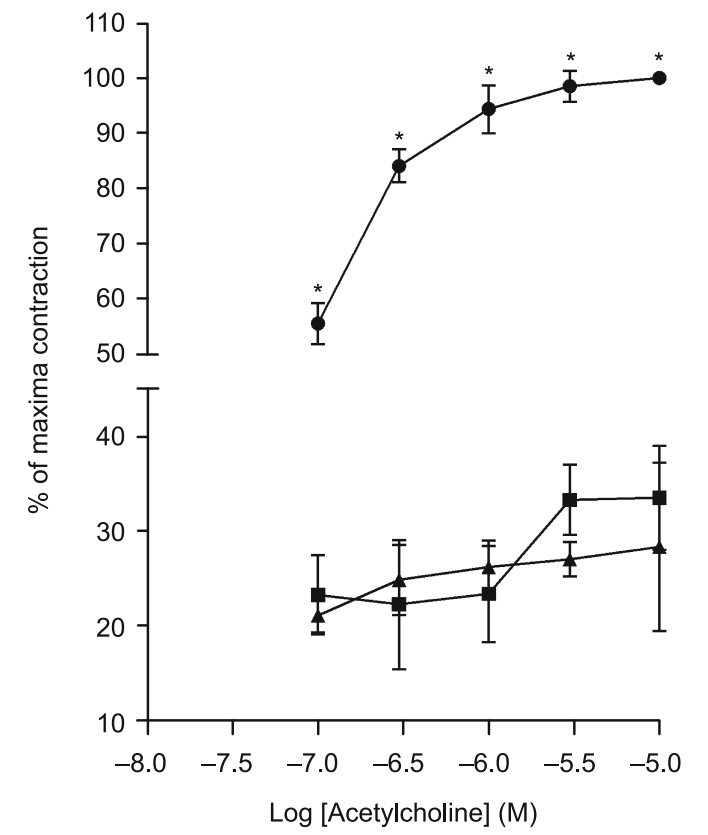

(B)

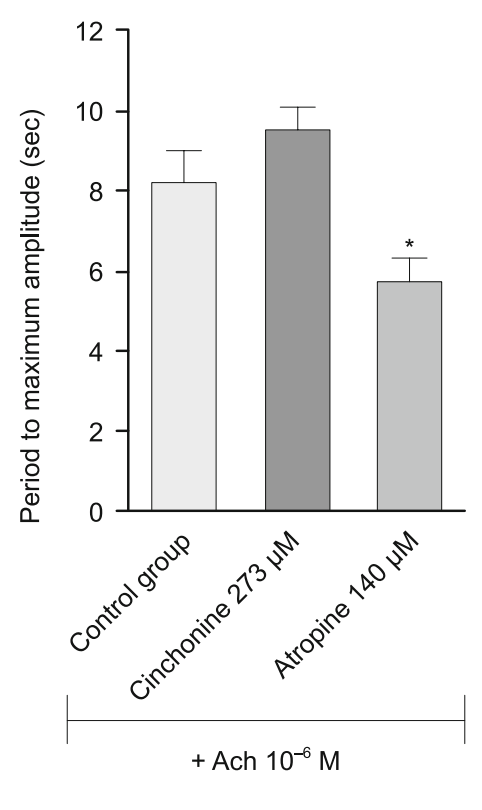

Fig. 3. (A) Effects of the Cin $(273 \mu \mathrm{M})$ and atropine $(140 \mathrm{nM})$ on the Ach-induced contractions of the isolated rat ileum. Curves showing the

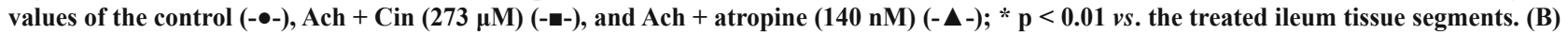
Measured PMA for the control, Cin and atropine-treated ileum tissue. Given data are the mean values \pm SD; *p $<0.01$ vs. the control ileum tissue segments.

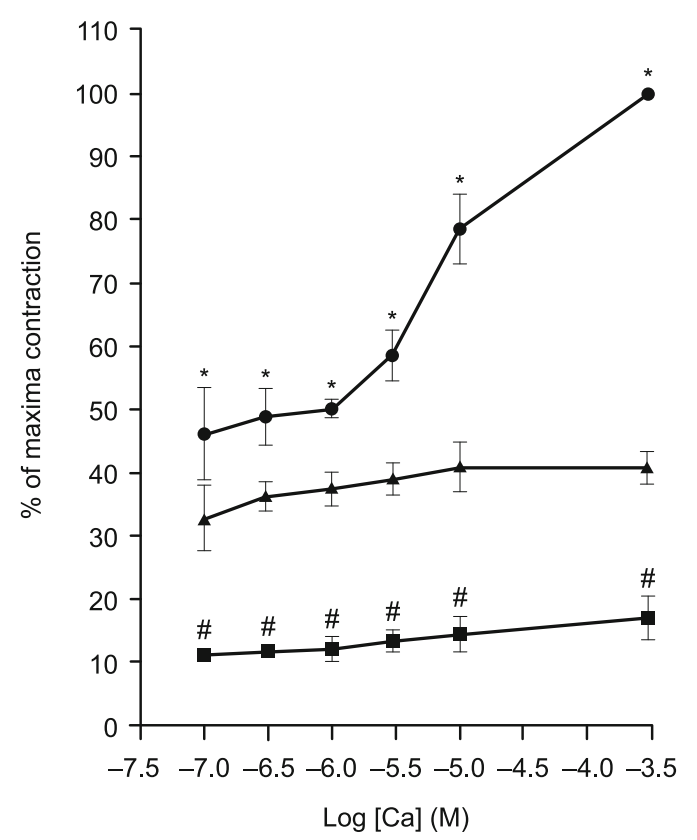

Fig. 4. Effects of $\mathrm{Cin}(273 \mu \mathrm{M})$ and verapamil $(1 \mu \mathrm{M})$ on the $\mathrm{Ca}^{2+}$-induced contractions of the isolated rat ileum. Curves showing the values

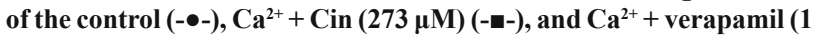
$\mu \mathrm{M})(-\Delta-)$. Each point represents the mean values as the percentage of the maximal response \pm SD of 6 segments. * $p<0.01$ vs. the treated tissue segments; ${ }^{\#} \mathbf{p}<0.01$ vs. the verapamil-treated tissue segments. measured PMA indicates whether the contraction of ileum tissue is mediated through the myenteric plexus or indirectly through the diffuse intestinal neuroendocrine system (10). Although PMA after Ach application remained unaffected by Cin (Fig. 3B), the intensity of tonic contractions was significantly diminished (Fig. 3A). Similar results have been recently published for quinine (10), where $100 \mu \mathrm{M}$ of quinine had no effect on PMA but reduced the tonic contractions evoked by $100 \mathrm{ng} / \mathrm{ml}$ of Ach. Based on the poor affection of PMA and a significant reduction in the contraction intensity, as well as on the findings of previous studies suggesting the involvement of serotoninergic receptors and enterochromaffin cells in the mechanism of action of quinine (16), the authors indicated a possible involvement of some different mechanism other than the one directly involving the myenteric plexus (10).

The application of increasing concentrations of $\mathrm{Ca}^{2+}$ ions to ileum tissue segments incubated in a calcium-free Tyrode's solution caused tonic contractions (Fig. 4). Incubation with either Cin at its $\mathrm{IC}_{50}$ concentration or verapamil $(1 \mu \mathrm{M})$ statistically significantly prevented the contraction occurrence (Fig. 4). The activity of Cin, although in almost 300-fold higher concentration, was found to be significantly stronger in preventing the contraction occurrence than the one of verapamil (Fig. 4). Depolarisation occurring after the exposure to high contractions of $\mathrm{Ca}^{2+}$, in its previous absence, is known to be mediated through voltage-dependent L-type calcium channels, however, a small portion of depolarisation might be related to $\mathrm{Ca}^{2+}$ voltage-independent channels (17). Cinchonine was previously found to affect $\mathrm{Ca}^{2+}$ channels function in human platelets, thus inhibiting coagulation (7). However, the calcium 


\section{$576-580$}

channels mainly involved in the contractions of smooth muscle cells located in the intestines are voltage-dependent (18), while the ones involved in platelet function (e.g. change in cell shape) are different types of ligand-mediated $\mathrm{Ca}^{2+}$ channels (19).

Cinchonine and verapamil, a known blocker of voltage-dependent calcium channels, share a number of structural features: the presence of a centrally placed basic tertiary amine, terminally displaced aromatic cores, and similarly oriented functional groups capable of forming hydrogen bonds, all are bioisosterically mutually located to interact with the target biomolecule. There are two major differences: the aromatic cores differ in the electron density, and the conformational freedom-flexibility of the molecules is distinct. It might be that they interact with the same biotarget, even the same region of the molecules, but this needs to be ascertained in future experiments.

The herein presented results show that Cin produces a decrease in spontaneous isolated rat ileum contractions, with an $\mathrm{IC}_{50}$ value of $273 \mu \mathrm{M}$. Studies conducted in order to determine the potential mechanism of action of Cin revealed that this alkaloid inhibits both Ach- and $\mathrm{Ca}^{2+}$-induced contractions. Based on these preliminary studies, one can say that Cin significantly affects the motor function of the gastrointestinal tract via mechanisms that most probably involve $\mathrm{Ca}^{2+}$ ions. However, this effect is operational at concentrations up to 100 times higher than that, in which the related more toxic alkaloid, quinine, acts.

\section{References}

1. Christensen SB Drugs and drug leads based on natural products for treatment and prophylaxis of malaria. 307-319. In: Mukherje PK (Ed). Evidence-based validation of herbal medicine. Oxford: Elsevier, 2015.

2. Rasoanaivo P, Wright CW, Willcox ML, Gilbert B. Whole plant extracts versus single compounds for the treatment of malaria: synergy and positive interactions. Malaria J 2011; 10: S4.

3. Tracy JW, Webster LT Drugs used in the chemotherapy of protozoal infections. 987-1008. In: Hardman JG, Limbird LE (Eds). The Pharmacological Basis of Therapeutics. New York: McGraw-Hill Book Co., 1996.

4. Kacprzak KM Chemistry and Biology of Cinchona Alkaloids. 605-641 In: Ramawat K Mérillon JM. (Eds). Natural Products. Berlin: Springer, 2013

5. Genne P, Duchamp O, Solary E, Pinard D, BelonJP, Dimanche-Boitrel MT, Chauffert B. Comparative effects of quinine and cinchonine in reversing multidrug resistence on human leukemic cell line K562/ADM. Leukemia 1994; 8: 160-164.
6. Jung SA, Choi M, Kim S, Yu R, Park T. Cinchonine prevents high-fatdiet-induced obesity through downregulation of adipogenesis and adipose inflammation. PPAR Res 2012; 2012: 541204.

7. Shah BH, Nawaz Z, Virani SS, Ali IQ, Saeed SA, GilaniAH. The inhibitory effect of cinchonine on human platelet aggregation due to blockade of calcium influx. Biochem Pharmacol 1998; 56: 955-960.

8. Luzzi GA, Peto TE. Adverse effects of antimalarials. An update. Drug Saf 1993; 8: 295-311.

9. Bateman DN, Dyson EH. Quinine toxicity. Adverse Drug React Acute Poisoning Rev 1986; 5: 215-233.

10. Yamashita A, Shimamoto N, Morita K, Sugiyama H, Kimoto M, Toda K, Ota M. Thiamine and quinine differently inhibit the early phase of acetylcholine-dependent contraction of mouse ileum in vitro. Int J Food Sci Nutr 2018; 7: 94-99.

11. Huddart H, Saad KH Quinine and lanthanum effects on contractility and calcium movements of rat ileal smooth muscle. Gen Pharmacol 1977; 8: 341-347.

12. Martínez-Pérez EF, Juárez ZN, Hernández LR, Bach H. Natural antispasmodics: source, stereochemical configuration, and biological activity. BioMed Res Internat 2018; 2018: 3819714.

13. Parker I, Ito Y, Kuriyama H,Miledi R. Beta-adrenergic agonists and cyclic AMP decrease intracellular resting free-calcium concentration in ileum smooth muscle. Proc R Soc Lond B Biol Sci 1987; 230: 207-214.

14. Theobald TC, Syson AJ, Burrin DH. The effect of caffeine and quinine on calcium efflux and cyclic AMP levels in bovine ileal smooth muscle. Comp Biochem Physiol 1978; C61: 395-400.

15. Go ML, Lee HS. Action of mefloquine on agonist-induced contractions of the guinea-pig isolated ileum. Clin Exp Pharmacol Physiol 1988; 15: $427-431$.

16. Kelley SP, Walsh J, Kelly MC, Muhdar S, Adel-Aziz M, Barrett ID, Wildman SS. Inhibition of native 5-HT3 receptor-evoked contractions in guinea pig and mouse ileum by antimalarial drugs. Eur J Pharmacol 2014; 738: 186-191.

17. Unno T, Matsuyama H, Sakamoto T, Uchiyama M, Izumi Y, Okamoto H, Yamada M, Wess J, Komori S. M(2) and M(3) muscarinic receptor-mediated contractions in longitudinal smooth muscle of the ileum studied with receptor knockout mice. Brit J Pharmacol 2005; 46: 98-108.

18. Zamponi GW, Striessnig J, Koschak A, Dolphin C. The physiology, pathology, and pharmacology of voltage-gated calcium channels and their future therapeutic potential. Pharmacol Rev 2015; 67: 821-870.

19. Mahaut-Smith MP The unique contribution of ion channels to platelet and megakaryocyte function. J ThrombHaemost 2010; 10: 1722-1732.

Received April 16, 2019. Accepted May 29, 2019. 